\title{
Selective laser melting of iron-based powder
}

\author{
J.P. Kruth ${ }^{\mathrm{a}, *}$, L. Froyen ${ }^{\mathrm{b}}$, J. Van Vaerenbergh ${ }^{\mathrm{a}}$, P. Mercelis ${ }^{\mathrm{a}}$, M. Rombouts ${ }^{\mathrm{b}}$, B. Lauwers ${ }^{\mathrm{a}}$ \\ a Department of Mechanical Engineering, Katholieke Universiteit Leuven, Leuven, Belgium \\ b Department of Metallurgy and Materials Engineering, Katholieke Universiteit Leuven, Leuven, Belgium
}

Accepted 14 November 2003

\begin{abstract}
Selective laser melting (SLM) is driven by the need to process near full density objects with mechanical properties comparable to those of bulk materials. During the process the powder particles are completely molten by the laser beam. The resulting high density allows avoiding lengthy post-processing as required with selective laser sintering (SLS) of metal powders. Unlike SLS, SLM is more difficult to control. Because of the large energy input of the laser beam and the complete melting of particles problems like balling, residual stresses and deformation occur. This paper will describe SLM applied to a mixture of different types of particles $\left(\mathrm{Fe}, \mathrm{Ni}, \mathrm{Cu}\right.$ and $\left.\mathrm{Fe}{ }_{3} \mathrm{P}\right)$ specially developed for SLM. The different appearing phenomenons are discussed and the process optimization is described. The latter includes an appropriate process parameter adjustment and the application of special scanning strategies. Resulting parts are characterized by their microstructure, density and mechanical properties.
\end{abstract}

(C) 2004 Elsevier B.V. All rights reserved.

Keywords: Selective laser melting; Selective laser sintering; Thermal deformations

\section{Introduction}

Selective laser sintering (SLS) was developed in the late 1980s, as a layer manufacturing process that was used for rapid prototyping [1,2]. Later on it also becomes a common technology to produce products for long-term use. The success of SLS as a rapid prototyping and rapid manufacturing technology results mainly from the ability to process almost any type of material. For the production of functional metallic prototypes, parts or tools, a high density is desired. This can be obtained through different powder binding mechanisms $[3,4]$ from which the selective laser melting (SLM) process $[5,6]$ is eligible. In SLM near full density parts can be produced without the need for post-processing steps, while the same materials can be used as in serial production. In order to reach a high density, the metallic powder particles are fully molten. Consequently the laser melting process is accompanied by the development of residual stresses, which arise from the high thermal gradients present in the material. These stresses can lead to part failure due to distortions, delamination or cracking. Besides the thermal stresses, the balling effect is also a severe impediment to interlayer connection. A last phenomenon discussed is the vaporization

\footnotetext{
* Corresponding author. Tel.: +32-16-32-24-90; fax: +32-16-32-29-87. E-mail address: jean-pierre.kruth@mech.kuleuven.ac.be (J.P. Kruth).
}

effect noticed when the powder bed is irradiated with high energy intensities. The influence of these phenomena is discussed and possible solutions are handed.

\section{Powder properties}

The powder used in this study is aiming at high density and good mechanical properties [4]. It is a mixture consisting of $50 \mathrm{wt} . \% \mathrm{Fe}, 20 \mathrm{wt} . \% \mathrm{Ni}, 15 \mathrm{wt} . \% \mathrm{Cu}$ and $15 \mathrm{wt} . \%$ $\mathrm{Fe}_{3} \mathrm{P}$. The grain size is below $60 \mu \mathrm{m}$ for the $\mathrm{Fe}, \mathrm{Cu}$ and $\mathrm{Fe}_{3} \mathrm{P}$ particles and below $5 \mu \mathrm{m}$ for Ni. All the particles are spherical except Fe. In choosing the appropriate powder mixture some considerations are taken into account. The addition of a melting point lowering additive, e.g. $\mathrm{Fe}_{3} \mathrm{P}$ or $\mathrm{Cu}_{3} \mathrm{P}$ is favorable in making the process more energy efficient. For instance, pure $\mathrm{Fe}$ has a melting point of $1538^{\circ} \mathrm{C}$, but after alloying with some small amount of $\mathrm{P}$ this can be lowered to $1048^{\circ} \mathrm{C}$ [7]. The dissolution of $\mathrm{P}$ in $\mathrm{Fe}$ also has the benefit of lowering the surface tension of the melt $[8,9]$. This lowers the tendency to form balls after melting and thus enhances the surface quality and density. Moreover P lowers the oxidation rate of the $\mathrm{Cu}$ and $\mathrm{Fe}$ powder particles. A last effect is an increase in hardness. $\mathrm{Ni}$ is added for its marked strengthening effect although its toxicity makes it an unpopular material. Attention is also paid to the compatibility of the different elements: they form intermetallic phases like 
$(\mathrm{Fe}, \mathrm{Ni})_{3} \mathrm{P}$. The powder has an apparent density of $3.17 \mathrm{~g} / \mathrm{cm}^{3}$ and a true density of $8.01 \mathrm{~g} / \mathrm{cm}^{3}$.

\section{Experimental conditions}

The machine used to perform the experiments was built at the University of Leuven. It uses a Rofin-Sinar Nd:YAG laser source with a wavelength of $1.064 \mu \mathrm{m}$ and a maximum output power of $300 \mathrm{~W}$ in continuous mode. Operation in pulsed mode with a frequency between 0 and $500 \mathrm{~Hz}$ is also possible. By means of a stepper motor the build platform can be moved with a resolution of $10 \mu \mathrm{m}$. Powder layers are deposited in one direction using a roller. The building stage is put in a vacuum chamber that can be filled with nitrogen or argon to prevent oxidation of the parts. Since it is not possible to fully eliminate deformations that lead to build failure, parts were manufactured on top of a substrate (base plate) bolted to the piston.

\section{Thermal deformations}

Many authors have discussed the role of thermal stresses in the SLS and SLM processes [10-14]. From all those contributions it becomes clear that both material properties of the processed powder and process parameters like scanning strategy, laser power, layer thickness, energy distribution etc. influence the appearance of thermal stresses in the part. In order to optimize the scanning strategy (scanning pattern) a closer look is taken to the different mechanisms involved during laser melting.

\subsection{Temperature gradient mechanism}

The temperature gradient mechanism (TGM) is commonly used for laser bending of sheets along straight lines $[15,16]$. However, this mechanism is also applicable in SLM where it acts on previously solidified layers lying underneath the processed powder layer. Due to the rapid heating of the upper surface by the laser beam and the rather slow heat conduction, a steep temperature gradient develops. The material strength simultaneously reduces due to a raise of temperature. Expansion of the heated top layer $\left(\varepsilon_{\mathrm{th}}\right)$ is converted into elastic and plastic compressive strains (see Fig. 1a) because of the fact that the surrounding material restricts a free expansion. When the material yield stress (which is lowered due to the high temperature) is reached, the top layer(s) will be plastically compressed $\left(\varepsilon_{\mathrm{pl}}, \sigma_{\text {comp }}\right)$. In absence of mechanical constraints, a counter bending away from the laser beam would be perceived. During cooling and shrinkage, the plastically compressed upper layers become shorter than the bottom layers and a bending angle towards the laser beam develops.

A link between this TGM for laser bending and the SLM process can be found [17]. The underlying, solidified layers in an SLM specimen are exposed to a comparable temperature gradient as mentioned in the TGM each time a new powder layer is being melted. In this way the generated stresses attempt to bend the consolidated layers towards the laser beam, which can cause distortion and part failure by delamination or cracking. Moreover the shrinkage of the molten layer(s) during cooling will add additional tensile stresses on top of the layers underneath that are influenced by the TGM. Only the temperature change below the melting point will result in additional stresses in the newly deposited layer. These stresses also tend to bend the part towards the laser.

\subsection{Different process temperatures}

Other internal stresses can be induced by time-varying processing temperatures, which can differ depending on the part geometry and the scan strategy used. Two causes for this difference can be mentioned.

Generally, cross-sections of the part are scanned with vectors parallel to each other. If the area to be scanned is small, a short scan vector length occurs. Hence, adjacent tracks are scanned rapidly one after the other, leaving little cool down time in between thus resulting in high temperatures (see Fig. 1b). For larger areas the laser beam travel distance is much longer and successively scanned tracks have more time to cool down leading to a lower temperature of the scanned area. Consequently worse wettings conditions are present leading to a lower density of the material.

Another reason for the different process temperatures can be explained by the difference in heat conductivity between the loose powder bed and the solidified material. During laser melting of the powder bed, the material density increases (e.g. from 40 to $95 \%$ of the true density). When scanning small zones surrounded by loose powder, it is likely that in comparison with large zones there is less heat sink due to the isolation of the surrounding powder. This is especially the case for zones at the corner of the part. At these locations a higher temperature will be the result, which can lead to better wetting conditions and higher material densities.

\subsection{Experiment}

To investigate the behavior of the above phenomena, specimens were scanned with different scanning patterns (strategies) and their deflection in Z-direction was measured. Therefore, base plates of $45 \mathrm{~mm} \times 22 \mathrm{~mm}$ were laser cut out of $1 \mathrm{~mm}$ thick steel plate. Before performing scanning tests, the plates were stress-free annealed in a furnace under reducing atmosphere. Fig. 2 depicts the compared scanning strategies and the applied parameters.

The first two scanning strategies, line $X$ and $Y$, are the patterns typically applied in SLS/SLM. For the other four strategies the part area is divided in small rectangular sectors of $5 \mathrm{~mm} \times 5 \mathrm{~mm}$ for strategy (3) and (4) and $2.5 \mathrm{~mm} \times 2.5 \mathrm{~mm}$ for the last two strategies. The order in which these sectors are being scanned can be successive (suc.) or according to 


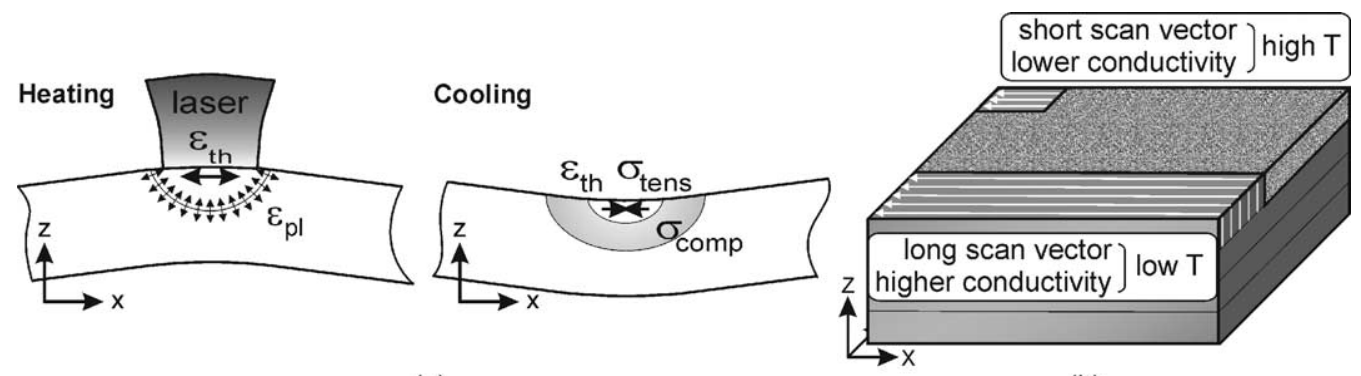

(a)

(b)

Fig. 1. (a) Temperature gradient mechanism, (b) different temperatures through different scan vector lengths.

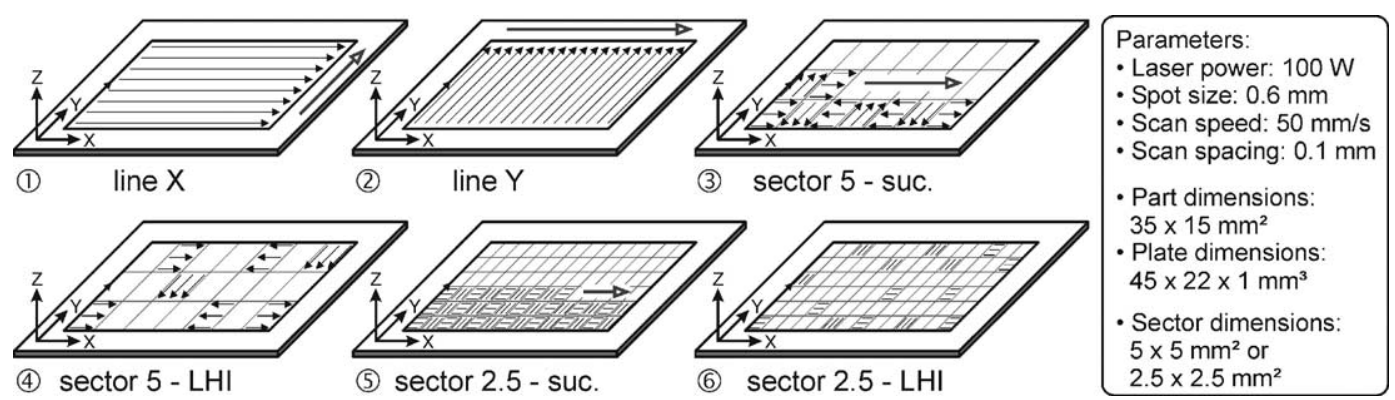

Fig. 2. The six different scanning strategies used in the comparison.

the least heat influence (LHI) between the scanned sectors. The successive scan order for strategy (3) and (5) starts with a line $X$ scanning of the sector at the left bottom of the part. The next sector (at the right) is scanned with a line $Y$ pattern, the next again with line $X$, etc. Also the starting corner for the line scan is varied for the subsequent sectors. The LHI method starts at a randomly selected sector. Next the sector which is least heated (thus farthest away from the last one) is scanned and so on. Between the subsequent sectors the orientation of the line scan is alternated between $X$ and $Y$. Parts are scanned under an inert nitrogen atmosphere.

These six scanning strategies are compared during two kinds of experiments: (a) scanning directly on the base plate and (b) melting one powder layer $(150 \mu \mathrm{m})$ on top of the base plate. Type (a) was chosen to eliminate the disturbing influence of a potential unequal distribution of powder particles in the layer or an uneven layer thickness. In case (b) it was not possible to melt multiple layers on top of each other because the warped samples prevent further layer deposition. To investigate deformations and internal stresses for multiple layer parts, further tests with the crack compliance method [18,19] are planned.

The unprocessed side of the bent plate was measured with a surface roughness meter (Rank Taylor Hobson Form Talysurf $120 \mathrm{~L}$ ) and the curvature along $X$ - and $Y$-direction was calculated from the obtained profile. A plot of the measured deflection for strategy (2) is depicted in Fig. 3a. Results for the curvature along $X$ of the samples with powder layer are
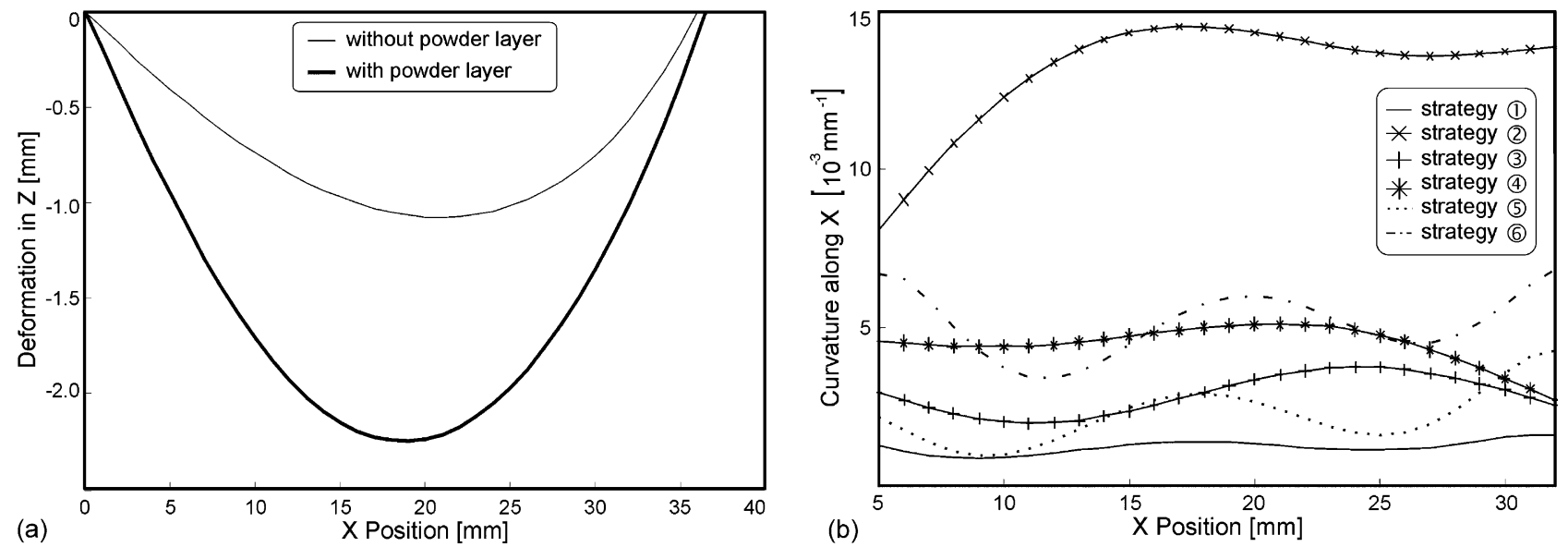

Fig. 3. (a) Deflection with and without powder layer for strategy (2), (b) plot of the curvature along the $X$-axis for the plate with powder layer. 

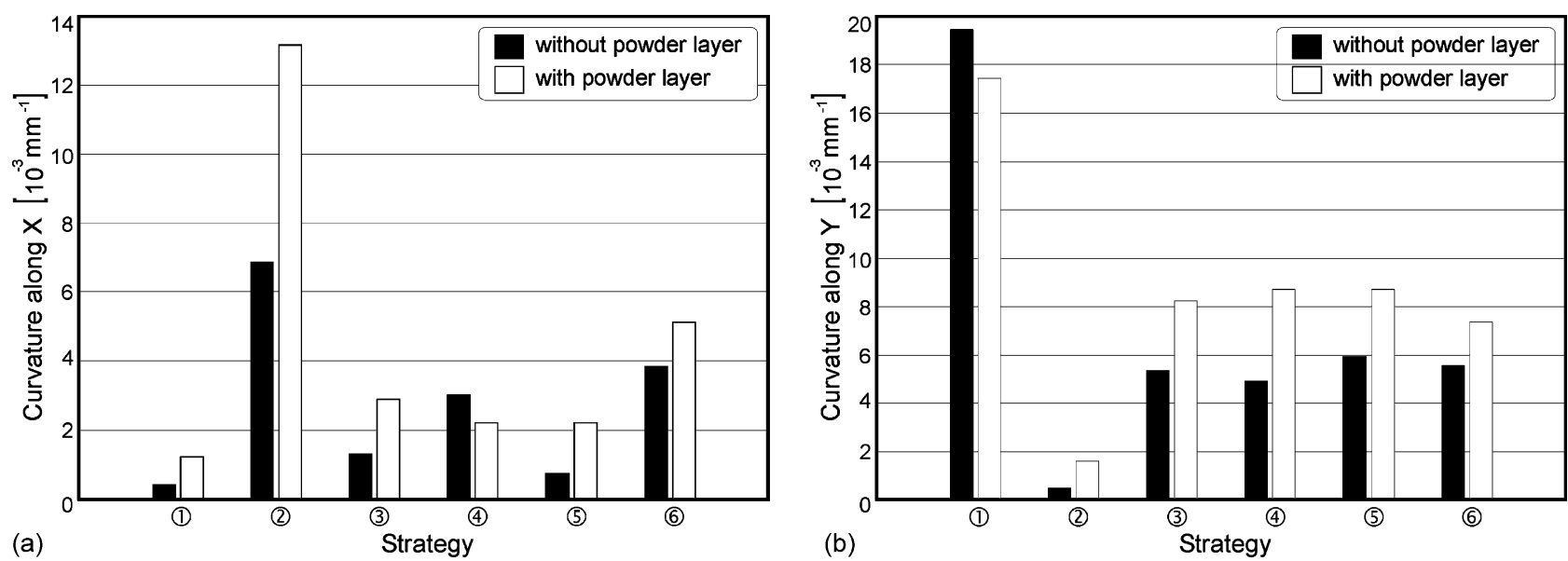

Fig. 4. The average curvature along (a) $X$-direction and (b) $Y$-direction.

presented in Fig. 3b. The average curvatures along $X$ - and $Y$-direction for scanning with and without a powder layer are shown in Fig. 4.

\subsection{Discussion}

Scanning along the $X$-direction-(1)-results in the smallest curvature in that direction, but the largest curvature in the $Y$-direction (vice versa for the $Y$ scanned part (2)). Similar results are predicted by finite element modeling [11].

Applying the sector wise scanning (3)-(6) results in less deformation; there are rather small curvatures along $X$ - and $Y$-directions. No striking difference in curvature between the large (3), (4) and the small (5), (6) sector strategies can be found. Nevertheless it must be noticed that in order to obtain the same melting behavior and the same temperature, the parts with small sectors could be scanned with less energy input from the laser, because of the shorter scan length as mentioned in Section 4.2. This would reduce the deformations caused by the TGM, thus favoring smaller sectors. The same conclusion can be made after finite element simulations [13].

When comparing the successive sector scanning (3), (5) and the LHI scanning (4), (6), it can be concluded that the successive method is preferable. A possible reason for the difference could be the higher thermal gradient obtained during LHI scanning. Indeed, the temperature of the sector before scanning is much lower compared to the successive method where successive sectors are somewhat preheated by the scanning of the previous sector.

The final state of stress in the part will be a superposition of the phenomena described earlier. The additional raise in thermal stresses caused by the solidification of the top layer can be clearly seen in Figs. 3a and 4, where the scanning with and without a powder layer are compared. This extra curvature superposed on the curvature caused by the TGM was found for all six strategies.

\section{Wettability}

Another disadvantageous phenomenon arising during SLM is balling. It occurs when the molten material does not wet the underlying substrate due to the surface tension, which tends to spheroidise the liquid. This results in a rough and bead-shaped surface, obstructing a smooth layer deposition and decreasing the density of the produced part.

Consider a flat, undeformable, perfectly smooth and chemically homogeneous solid surface (S) in contact with a non-reactive liquid $(\mathrm{L})$ in the presence of a vapor $(\mathrm{V})$ phase. This metastable equilibrium is depicted in Fig. 5a. If the liquid does not completely cover the solid, the liquid surface will intersect the solid surface at a contact angle $\theta$ that corresponds to a minimum of the total free energy of the system. The value of $\theta$ obeys the classical equation of Young (1804) (see Fig. 5a) [20]. Since the interaction time during laser melting is very short, order of magnitude of milliseconds, the equation of Young holds.

In reality the molten pool created by the moving laser spot can be approximated by a half cylinder. Therefore an additional reduction of the surface free energy appears: when the total surface of the molten pool becomes larger than that of a sphere with the same volume, the balling effect takes places (see Fig. 5b). Thus, the laser parameters should be selected in such a way that the length to diameter ratio of the molten pool is as small as possible [21].

A process window for continuous wave as well as for pulsed laser operation mode is experimentally determined. Similar process windows are also presented by [21]. In Fig. 6a, laser power $P$ and scan speed $v$ are varied for a single powder layer scanned on top of a base plate. The layer thickness is $0.25 \mathrm{~mm}$ and the applied scan spacing is $0.1 \mathrm{~mm}$. The spot of the laser beam has a diameter of $0.8 \mathrm{~mm}$. From this parameter study it is confirmed that high scan speeds combined with high laser powers result in less balling. This is because the melt pool rapidly resolidifies behind the laser spot, while the length of the molten track remains short. However, other studies $[22,23]$ have shown 


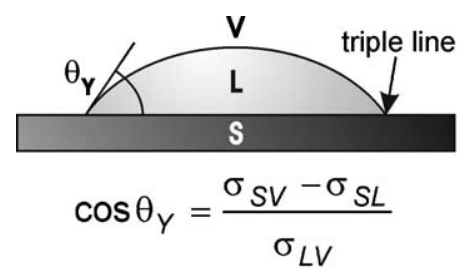

(a)

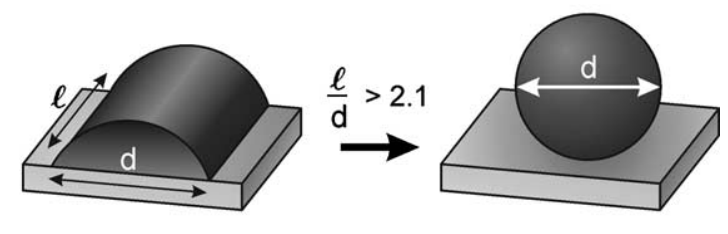

(b)

Fig. 5. (a) Wetting of a liquid on a solid substrate and equation of Young with $\sigma_{\mathrm{SV}}, \sigma_{\mathrm{SL}}$ and $\sigma_{\mathrm{LV}}$ the surface free energies of the system, (b) transition from half cylinder to sphere depending on the dimensions of the molten laser pool.

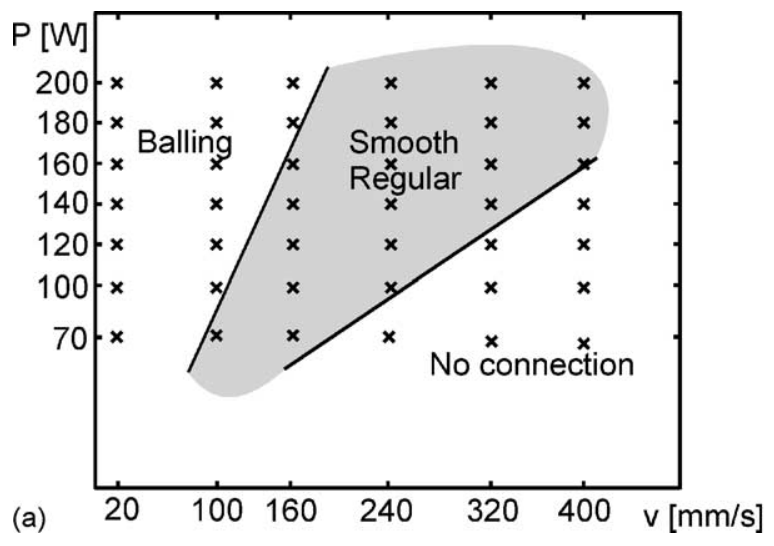

Fig. 6. Process window for (a) CW operation and (b) pulsed operation.

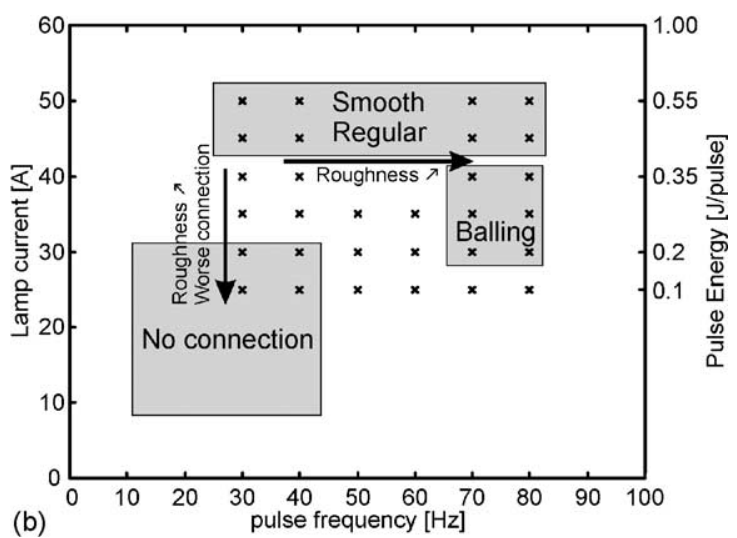

the opposite effect: no balling occurs at very low scan speeds and low laser powers (e.g. $1 \mathrm{~mm} / \mathrm{s}$ at $10 \mathrm{~W}$ ). A possible explanation is the widening of the scan track at these low velocities due to heat conduction. Because of the low building speed, this region was not investigated in this study.

In Fig. $6 \mathrm{~b}$ the laser is operated in pulsed mode with a pulse duration of $4 \mathrm{~ms}$ and a scan spacing of $0.2 \mathrm{~mm}$. The laser lamp current (corresponding to the peak power) and pulse frequency are varied. Four layers of powder are melted on top of a base plate. It was found that high peak powers promote a good interlayer connection $[3,24]$ and result in a higher attained temperature of the melt [25]. The latter has a positive effect on the balling phenomenon.

Since liquid metals do not wet surface oxide films in the absence of a chemical reaction, it is very important to avoid oxidation. Therefore sufficient remelting of the previous layer is necessary to remove surface contaminants, to break down oxide films and to provide a clean solid-liquid interface at the atomic level [20,26,27]. Another possibility to improve wetting is adding certain alloying elements, like $\mathrm{P}$ in this study. Finally a last method to suppress balling is applying very high pulse energies. This will be discussed in the next paragraph.

\section{Vaporization effect}

During laser melting the temperature of the exposed powder particles exceeds the melting temperature. A further in- crease of the temperature (to around $2857^{\circ} \mathrm{C}$ for $\mathrm{Fe}$ ) causes the material to evaporate. When this phase transformation occurs, the rapidly moving evaporated powder particles expand and generate a recoil pressure on the molten pool. At even higher incident intensities $\left(10^{5}\right.$ to $10^{6} \mathrm{~W} / \mathrm{mm}^{2}$ for a Nd:YAG laser), the vapor interacts with the laser radiation, becomes ionized and a plasma is formed $[28,29]$. While low recoil pressures facilitate the flattening of the melt in SLM, high pressures cause material removal by melt expulsion. The latter is used as an ablation technique in, e.g. evaporative laser milling [29].

The evaporation effect can be obtained by running the laser in pulsed mode. In that way, peak intensities up to $2 \times 10^{3} \mathrm{~W} / \mathrm{mm}^{2}$ are attained. At these power densities the favorable effect of evaporation is perceived: the balling effect is completely absent and the density of the solidified layer is improved. This leads to an improved surface quality and a higher strength of the produced part. Since the power intensity is some orders of magnitude lower then the plasma threshold, it can be concluded that only evaporation takes place. Yet it needs to be noticed that a strict comparison is not possible because of the low pressure $\left(10^{2} \mathrm{~Pa}\right)$ in the process chamber during the SLM experiments. Due to this low pressure, the evaporation temperature of, e.g. Fe drops from $2857^{\circ} \mathrm{C}$ at $10^{5} \mathrm{~Pa}$ to $1847^{\circ} \mathrm{C}$ at $133 \mathrm{~Pa}$ [30] thus less energy is required to evaporate the material. Moreover the plasma threshold as found in literature is valid for solid bulk materials having much higher heat conduction than the loose powder bed. 


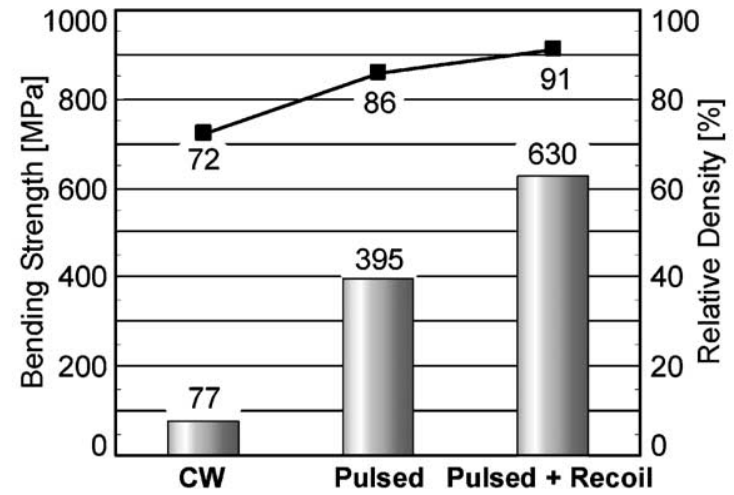

(a)

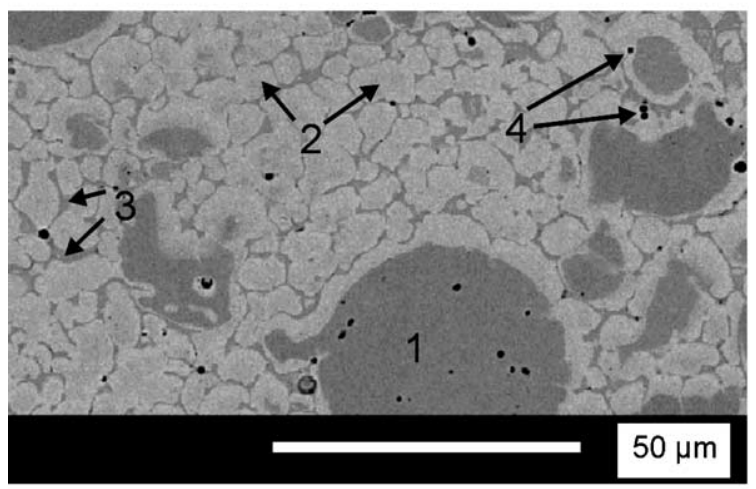

(c)

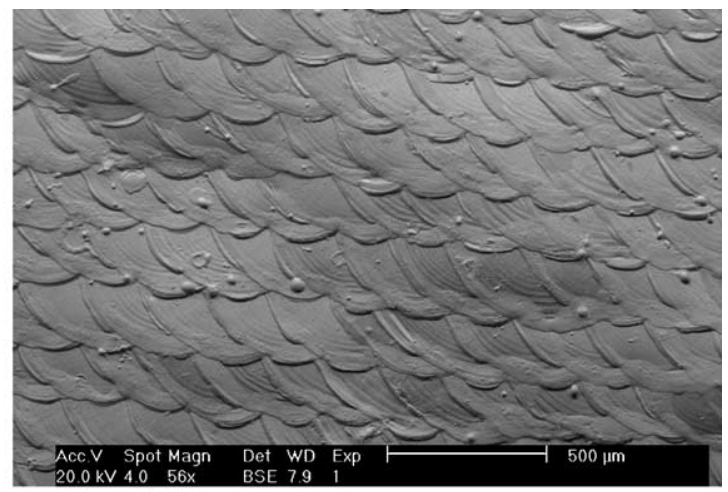

(b)

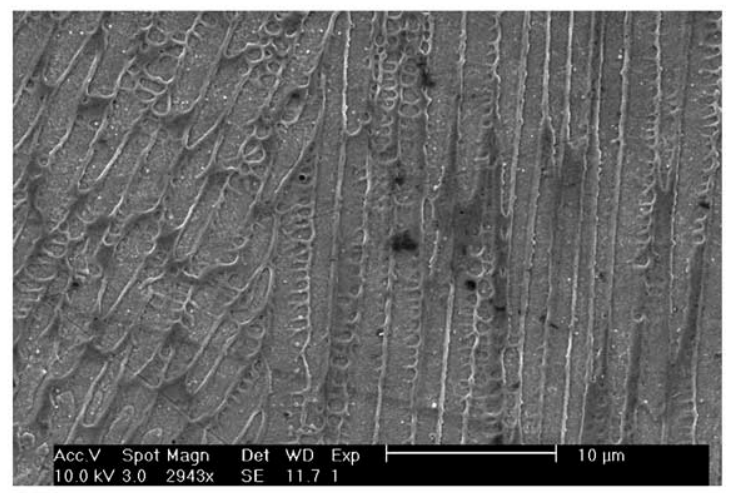

(d)

Fig. 7. (a) Bending strength and relative density for different laser regimes, (b) top surface of a part scanned with overlaying pulses, (c) micrograph showing remaining Fe particles (1), dendritic P-poor high-melting phase (2) surrounded by darker inter-granular P-rich divorced eutectic (3) and some residual porosity visual as black dots (4), (d) micrograph showing the typical fine rapid solidified microstructure.

\section{Mechanical properties}

The mechanical properties of SLM produced parts were investigated and related to the process parameters. The density of the parts was determined using the 'Archimedes-method' in ethanol.

Three point bending tests (according to the ASTM B312-82 standard) were done to determine the bending strength of the parts. Three main laser regimes may be distinguished: continuous mode, pulsed mode and pulsed mode with the recoil effect. As discussed the latter leads to an improved inter-layer connection. It can be seen on Fig. 7a that although the difference in relative density of the $\mathrm{CW}$ and pulsed parts is not so large, the difference in strength is. This is mainly caused by the bad interlayer connection that occurs with the $\mathrm{CW}$ scanning due to insufficient peak power. The surface of the parts produced with the evaporation regime exhibits a scale-like pattern. Fig. $7 \mathrm{~b}$ shows the top surface of a part produced with largely overlapping pulses (pulse distance $=0.17 \mathrm{~mm}$, laser beam diameter $=0.60 \mathrm{~mm}$ ).

Roughness values of 10-30 $\mu \mathrm{m} R_{\mathrm{a}}$ (without cut-off) were obtained for the presented SLM parts. These large values originate from pulse craters on the one hand, and droplets of material that were blown away and solidified elsewhere on the part surface on the other hand.

Depending on the peak intensity different types of microstructures were obtained. Fig. 7c shows the micrograph of a part scanned with a pulse power of $300 \mathrm{~W}$. It is clear that no full melting was achieved, since unmolten Fe particles remain visible. Raising the pulse power yields full melting and partial evaporation. The grains have a strong orientation (Fig. 7d) which embrittles the material and facilitates crack formation. However, as indicated before, these high peak intensities induce large thermal stresses yielding vertical cracks in the parts when the process parameters are not carefully selected.

\section{Conclusion}

This paper has demonstrated the importance of the processing parameters in striving to obtain full density metal parts by means of selective laser melting. Appearing deformation mechanisms were discussed and process conditions were optimized. Appropriate scanning patterns gave an appreciable reduction in thermal deformations and the beneficial effect of vaporization to restrain the balling effect was 
observed. Due to a higher degree of melting the density of the consolidated samples increased when the laser was operated in pulsed mode. A maximum bending strength of $630 \mathrm{MPa}$ was achieved at a material density of $91 \%$.

\section{Acknowledgements}

Research supported by national funding provided by OSTC, FWO and KUL-GOA.

\section{References}

[1] J.P. Kruth, Material incress manufacturing by rapid prototyping techniques, CIRP Ann. 40 (2) (1991) 603-614.

[2] D.L. Bourell, H.L. Marcus, J.W. Barlow, J.J. Beaman, Selective laser sintering of metals and ceramics, Int. J. Powder Metall. 28 (4) (1992) 369.

[3] J.P. Kruth, B. Van der Schueren, J.E. Bonse, B. Morren, Basic powder metallurgical aspects in selective metal powder sintering, CIRP Ann. 45 (1) (1996) 183-186.

[4] J.P. Kruth, P. Mercelis, J. Van Vaerenbergh, L. Froyen, M. Rombouts, Advances in selective laser sintering, in: Proceedings of the International Conference on Advanced Research in Virtual and Rapid Prototyping, 2003, pp. 59-70.

[5] W. Meiners, K. Wissenbach, R. Poprawe, Direct selective laser sintering of steel powder, in: Proceedings of the LANE'97, 1997, pp. 615-622.

[6] C. Over, W. Meiners, K. Wissenbach, M. Lindemann, J. Hutfless, Laser melting: a new approach for the direct manufacturing of metal parts and tools, in: Proceedings of the Euro-uRapid 2002 International User's Conference, 2002, A-5 pp.

[7] W.G. Moffatt, Handbook of Binary Phase Diagrams, General Electric Corporation, 1976.

[8] H. Herman, Treatise on Materials Science and Technology, Academic Press, New York, 1981, p. 120.

[9] J. Bénard, Adsorption on metal surfaces: an integrated approach, Stud. Surf. Sci. Catal. 13 (1983) 54.

[10] H. Pohl, A. Simchi, M. Issa, H.C. Dias, Thermal stresses in direct metal laser sintering, in: Proceedings of the Solid Freeform Fabrication Symposium, 2001, pp. 366-372.

[11] A.H. Nickel, D.M. Barnett, F.B. Prinz, Thermal stresses and deposition patterns in layered manufacturing, Mater. Sci. Eng. A 317 (2001) 59-64.

[12] K.W. Dalgarno, T.H.C. Childs, I. Rowntree, L. Rothwell, Finite element analysis of curl development in the selective laser sintering process, in: Proceedings of the Solid Freeform Fabrication Symposium, 1996, pp. 559-566.
[13] M. Matsumoto, M. Shiomi, K. Osakada, F. Abe, Finite element analysis of single layer forming on metallic powder bed in rapid prototyping by selective laser processing, Int. J. Mach. Tools Manuf. 42 (2002) 61-67.

[14] A.H. Nickel, Analysis of thermal stresses in shape deposition manufacturing of metal parts, Ph.D. Thesis, Department of Materials Science and Engineering, Stanford University, 1999.

[15] F. Vollertsen, Mechanisms and models for laser forming, in: Proceedings of the LANE'94, 1994, pp. 345-359.

[16] J. Duflou, J.P. Kruth, A. Rodriguez, Z. Huq, Laser bending with high power $\mathrm{CO}_{2}$ lasers, in: Proceedings of the Sheet Metal, 2003, pp. $97-106$.

[17] A. Coremans, D. Groot, Residual stresses and thermal stability of laser beam sintered metal parts, in: Proceedings of the LANE'97, 1997, pp. 577-588.

[18] D. Nowell, D.A. Hills, S. Tochilin, Use of the crack compliance method for the measurement of residual stress, in: Proceedings of the Sixth International Conference on Residual Stresses, 2000, pp. 845-852.

[19] M.B. Prime, Measuring residual stress and the resulting stress intensity factor in the compact tension specimens, Fatigue Fracture Eng. Mater. Struct. 22 (3) (1999) 195-204.

[20] N. Eustathopoulos, M.G. Nicholas, B. Drevet, Wettability at High Temperatures, Pergamon Press, Oxford, 1999.

[21] N.P. Karapatis, A sub-process approach of selective laser sintering, Ph.D. Thesis, Ecole Polytechnique Federal de Lausanne, 2001.

[22] H.J. Niu, T.H. Chang, Instability of scan tracks of selective laser sintering of high speed steel powder, Scripta Mater. 41 (11) (1999) 1229-1234

[23] C. Hauser, T.H.C. Childs, C.M. Taylor, M. Badrossamay, Direct selective laser sintering of tool steel powders to high density. Part A. Effect of laser beam width and scan strategy, in: Proceedings of the Solid Freeform Fabrication Symposium, 2003.

[24] R. Glardon, N. Karapatis, V. Romano, Influence of Nd:YAG parameters on the selective laser sintering of metallic powders, CIRP Ann. 50 (1) (2001) 133-136.

[25] M. Shiomi, A. Yoshidome, F. Abe, K. Osakada, Finite element analysis of melting and solidifying processes in laser rapid prototyping of metallic powders, Int. J. Mach. Tools Manuf. 39 (1999) 237252.

[26] F. Abe, K. Osakada, M. Shiomi, M. Matsumoto, M. Shiomi, The manufacturing of hard tools from metallic powders by selective laser melting, J. Mater. Process. Technol. 111 (2001) 210-213.

[27] S. Das, On some physical aspects of process control in direct selective laser sintering of metals, in: Proceedings of the Solid Freeform Fabrication Symposium, 2001, pp. 85-109.

[28] M. Von Allmen, Laser-beam Interactions with Materials, Springer-Verlag, Berlin, 1987.

[29] F. Wisselink, Use of the plume initiation time in laser milling, Ph.D. Thesis, Universiteit Twente, 1996.

[30] A. Guthrie, Vacuum Technology, Wiley, New York, 1963, p. 217. 